\title{
Tratamiento de agua para consumo humano
}

\author{
Nadia Cristina Chulluncuy Camacho \\ Universidad Nacional Mayor de San Marcos \\ Ingeniería Industrial n²9, 2011, ISSN 1025-9929, pp. 153-170 \\ Recibido: 23 de mayo del 2011 / Aprobado: 16 de junio del 2011
}

RESUMEN: Las diversas actividades generadas por el hombre han provocado una modificación de las características de los recursos hídricos, alcanzando niveles de contaminación que hacen el agua no apta para consumo humano, por esta razón los procesos para tratar el agua son cada vez más complejos. El agua potable debe estar libre de microorganismos patógenos, sustancias tóxicas o nocivas para la salud, y cumplir con las normas bacteriológicas y fisicoquímicas establecidas. El agua es un recurso valioso y escaso, por lo tanto la población debe utilizarla de forma racional.

Palabras clave: agua potable / calidad del agua / tratamiento del agua / Perú

\section{Treating water for human consumption}

ABSTRACT: The various man-made activities have caused a change in the characteristics of water resources, reaching levels of pollution that make the unsuitable water for human consumption, is for this reason that the water treatment processes are becoming more complex. Drinking water must be free of pathogens, toxic or harmful to health, compliance the bacteriological and physicochemical standards established.

Water is a scarce and valuable resource; therefore the population must use it rationally.

Keywords: drinking water / drinking water quality/ water treatment / Perú 


\section{INTRODUCCIÓN}

El crecimiento de la población y el desarrollo industrial han multiplicado los problemas de contaminación del agua tanto de procedencia superficial como subterránea.

La contaminación del agua es producida principalmente por vertimiento de aguas servidas, basura, relaves mineros y productos químicos. En estas condiciones el ciclo del agua ya no tiene la capacidad suficiente para limpiarla, por ello, se requieren diversos procesos para desinfectarla y hacerla apta para consumo humano.

La complejidad de los procesos que constituyen el tratamiento del agua va a depender de las características del agua superficial que se va a tratar; por este motivo, es necesario preservar la calidad del agua desde la fuente para evitar no solo costos ecológicos y sociales sino también económicos.

La evaluación continua de la calidad del agua comprende las siguientes fases: fuente, tratamiento, almacenamiento y distribución a la población.

Un aspecto importante a considerar en el tratamiento del agua es la producción de aguas residuales, que se deben gestionar adecuadamente para su posible reutilización o reciclaje.

\section{CALIDAD DEL AGUA}

El agua es de vital importancia para el ser humano, ya que al ser considerado el solvente universal, ayuda a eliminar las sustancias que resultan de los procesos bioquímicos producidos en el organismo. Sin embargo, también puede transportar sustancias nocivas al organismo, ocasionando daños en la salud de las personas.

Las fuentes de agua que abastecen a una población pueden proceder de la lluvia, de aguas superficiales o de aguas subterráneas. El agua que se trata para consumo humano es de origen superficial.

En la siguiente tabla se clasifican los contaminantes presentes en el agua. 
Tabla 1

Clasificación de los contaminantes presentes en el agua

\begin{tabular}{llll}
\hline Físicos & Químicos & Gaseosos & Biológicos \\
\hline Color & Materia orgánica & Anhídrido carbónico & Bacterias \\
Olor y sabor & Acidez lalcalinidad & Metano & Hongos \\
Grasas y aceites & $\mathrm{pH}$ & Ácido sulfhídrico & Protozoos \\
Espumas & Nitrógeno & & Algas \\
Radiactividad & Fósforo & Animales \\
Temperatura & Salinidad & Plantas \\
Sólidos disueltos & Metales pesados & Virus \\
Sólidos en suspensión & Detergentes & \\
& Compuestos tóxicos & & \\
& Pesticidas & &
\end{tabular}

Fuente: Funiber (2011).

Estos contaminantes pasan por diferentes procesos con el objetivo de que el agua llegue a cumplir los límites máximos permisibles establecidos para los parámetros que se muestran en la tabla 2. En el Perú, los análisis para el control del proceso y de la calidad de las aguas tratadas se hacen de acuerdo con las Directivas sobre Desinfección de Agua para Consumo Humano de la Sunass, la Norma Técnica Peruana 214.003 del Instituto Nacional de Defensa de la Competencia y de Protección de la Propiedad Intelectual (Indecopi), y complementariamente, por las normas aplicables de la Organización Mundial de la Salud (OMS), la American Water Works Association (AWWA) o del American National Standars Institute (ANSI) .

Tabla 2

Calidad del agua

\begin{tabular}{lcc}
\hline \multicolumn{1}{c}{ Parámetro o característica } & Unidad & LMP \\
\hline Físico & & \\
Color & UCV & 20 \\
Conductividad & $\mu S / c m$ & 1500 \\
Olor & & -- \\
Temperatura & OC & -- \\
Turbiedad & NTU & 5 \\
\hline
\end{tabular}

(continúa) 
(continuación)

\begin{tabular}{lcc}
\hline \multicolumn{1}{c}{ Parámetro o característica } & Unidad & LMP \\
\hline Microbiológico & & \\
Coliformes totales & UFC/100 mL & 0 \\
Coliformes termotolerables & UFC/100 mL & 0 \\
Bacterias heterotróficas & $\mathrm{UFC} / \mathrm{mL}$ & 500 \\
Compuestos inorgánicos & & \\
Aluminio & $\mathrm{mg} / \mathrm{L}$ & 0.2 \\
Cadmio & $\mathrm{mg} / \mathrm{L}$ & 0.003 \\
Cloruro & $\mathrm{mg} / \mathrm{L}$ & 250 \\
Cobre & $\mathrm{mg} / \mathrm{L}$ & 3 \\
Dureza & $\mathrm{mg} / \mathrm{L}$ & 500 \\
Fluoruros & $\mathrm{mg} / \mathrm{L}$ & 2 \\
Hierro & $\mathrm{mg} / \mathrm{L}$ & 0.3 \\
Manganeso & $\mathrm{mg} / \mathrm{L}$ & 0.2 \\
Mercurio & $\mathrm{mg} / \mathrm{L}$ & 0.001 \\
Nitratos & $\mathrm{mg} / \mathrm{L}$ & 50 \\
pH & & $6.5-8.5$ \\
Plomo & $\mathrm{mg} / \mathrm{L}$ & 0.1 \\
Selenio & $\mathrm{mg} / \mathrm{L}$ & 0.05 \\
Sulfatos & $\mathrm{mg} / \mathrm{L}$ & 250 \\
\hline
\end{tabular}

Fuente: Sunass (2000).

\section{PRINCIPALES PROCESOS EMPLEADOS EN EL TRATAMIENTO DE AGUA PARA CONSUMO HUMANO}

En el tratamiento del agua para consumo humano se emplean diferentes procesos; la complejidad de estos dependerá de las características del agua cruda. A continuación describiremos los principales:

\subsection{Cribado}

En este proceso se eliminan los sólidos de mayor tamaño que se encuentran en el agua (ramas, madera, piedras, plásticos, etcétera) por medio de rejas, en las que estos materiales quedan retenidos.

\subsection{Coagulación-floculación}

La coagulación consiste en la adición de coagulantes con el fin de desestabilizar las partículas coloidales para que sean removidas. Este pro- 
ceso ocurre en fracciones de segundo, depende de la concentración del coagulante y del pH final de la mezcla. Mientras que la floculación es el proceso por el cual las partículas desestabilizadas chocan entre sí y se aglomeran formando los floc.

En estos procesos, aparte de la remoción de turbiedad y color también se eliminan bacterias, virus, organismos patógenos susceptibles de ser separados por coagulación, algas y sustancias que producen sabor y olor en algunos casos.

El proceso de coagulación-floculación requiere ser controlado con mucho cuidado por ser una de las fases más importantes del tratamiento, ya que de este dependerá la eficiencia de los sedimentadores y filtros.

En las plantas de tratamiento, la coagulación se lleva a cabo en la unidad denominada mezcla rápida y la floculación se realiza en floculadores.

En la figura 1 se observa que la mezcla rápida está constituida por canales Parshall y es allí donde se produce la inyección del coagulante, mientras que en la figura 2 se observan floculadores con pantallas y flujo vertical.

Figura 1

Mezcla rápida: Canales Parshall

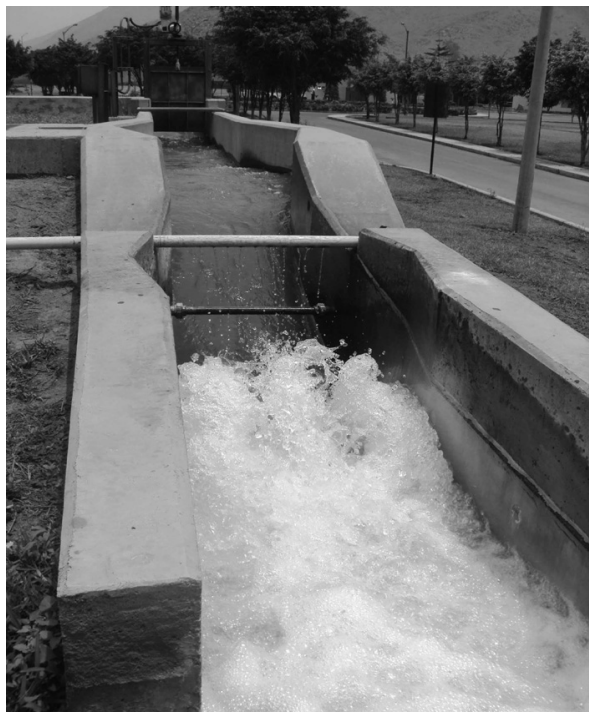

Fuente: Consorcio Agua Azul (2011).
Figura 2

Mezcla rápida: Canales Parshall

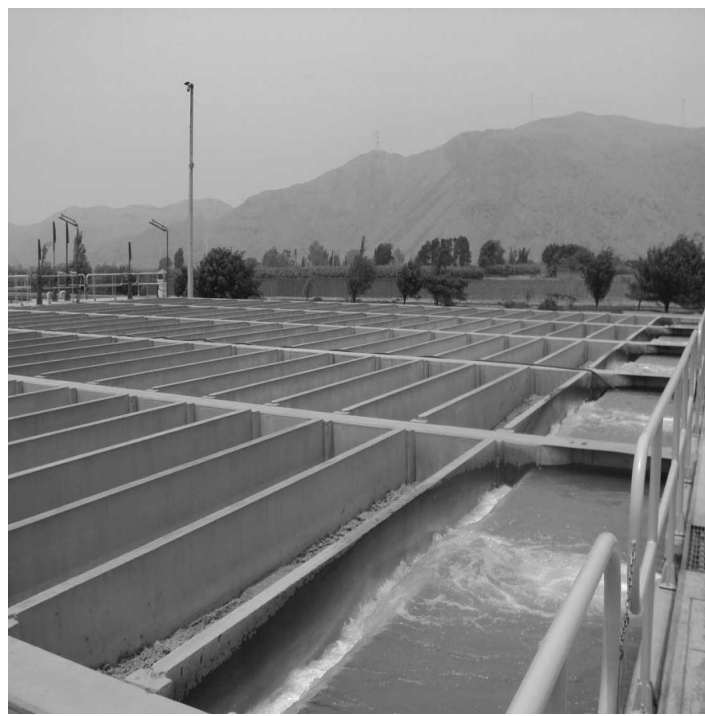

Fuente: Consorcio Agua Azul (2011). 
Respecto a los coagulantes es recomendable darles el tiempo suficiente para que las partículas del compuesto se disuelvan. Los coagulantes más usados son: sulfato de aluminio, cloruro férrico y sulfato férrico. Asimismo, se emplean ayudantes de coagulación, como polímeros catiónicos o aniónicos.

Para determinar la dosis óptima de coagulante se realizan ensayos de prueba de jarras, que simulan las condiciones de coagulación-floculación de la planta, buscando obtener el floc pesado y compacto que pueda quedar fácilmente retenido en los sedimentadores y que no se rompa al pasar los filtros.

En las pruebas de jarras se determina el tamaño del floc producido a través del índice de Willcomb, el tiempo inicial de formación del floc y la turbiedad residual después de un periodo de decantación no inferior a diez minutos; se escoge como dosis óptima la jarra que presenta el floc más grande, mayor velocidad de asentamiento y menor turbiedad residual.

Las siguientes tablas muestran los resultados obtenidos en las pruebas de jarras realizadas en el laboratorio de la planta de tratamiento de agua de la empresa Consorcio Agua Azul S.A., ubicado en el distrito limeño de Carabayllo, las cuales detallaremos en el apartado siguiente.

La tabla 3 utiliza como coagulante sulfato de aluminio $(50 \% \mathrm{v} / \mathrm{v})$, mientras que la tabla 4 utiliza sulfato férrico.

Características del agua cruda (agua del río Chillón):

- Turbiedad: 20 NTU.

- $\mathrm{pH}: 8.21$.

- Temperatura: $21,4{ }^{\circ} \mathrm{C}$.

- Dureza total: $239.2 \mathrm{mg} / \mathrm{l} \mathrm{CaCO}_{3}$.

- Alcalinidad: $102.7 \mathrm{mg} / \mathrm{l}$.

En la tabla 3 se observa que la dosis correcta es la que corresponde a la jarra $\mathrm{N}^{\circ} 2$, al obtener un floc bueno, según el índice de Willcomb, con una turbiedad residual menor que las anteriores, y en la tabla 4 la dosis correcta corresponde a la jarra $\mathrm{N}^{\circ} 4$. Comparando ambos coagulantes, los dos producen un floc compacto y se obtiene una turbiedad residual baja. Sin embargo, la diferencia entre ambos radica en el aspecto económico, puesto que la tonelada de sulfato de aluminio cuesta menos de la mitad de lo que costaría empleando el sulfato férrico. 
Tabla 3

Prueba de jarras con sulfato de aluminio

\begin{tabular}{|c|c|c|c|c|c|c|c|}
\hline & \multicolumn{2}{|c|}{ Mezcla rápida } & \multicolumn{4}{|c|}{ Floculación } & Sedimentación \\
\hline \multirow{3}{*}{$\begin{array}{c}\text { Jarras } \\
\mathbf{N}^{\circ}\end{array}$} & Tiempo (s) & 3 & $\begin{array}{l}\text { Tiempo } \\
\text { (minutos) }\end{array}$ & 6 & 6 & 6 & $\begin{array}{l}\text { Tiempo (minu- } \\
\text { tos) }\end{array}$ \\
\hline & $\begin{array}{l}\text { Velocidad } \\
\text { (RPM) }\end{array}$ & 300 & $\begin{array}{l}\text { Velocidad } \\
\text { (RPM) }\end{array}$ & 70 & 30 & 20 & 12 \\
\hline & Coag. (ml) & $\begin{array}{l}\text { Coag. } \\
\text { (ppm) }\end{array}$ & $\begin{array}{l}\text { Tiempo form. } \\
\text { floc (s) }\end{array}$ & \multicolumn{3}{|c|}{$\begin{array}{l}\text { Índice de } \\
\text { Willcomb }\end{array}$} & $\begin{array}{l}\text { Turbiedad resi- } \\
\text { dual (NTU) }\end{array}$ \\
\hline 1 & 0,6 & 15 & 90 & \multicolumn{3}{|c|}{8} & 0,77 \\
\hline 2 & 0,72 & 18 & 80 & \multicolumn{3}{|c|}{8} & 0,54 \\
\hline 3 & 0,8 & 20 & 70 & \multicolumn{3}{|c|}{6} & 1,49 \\
\hline 4 & 1 & 25 & 60 & \multicolumn{3}{|c|}{6} & 1,30 \\
\hline
\end{tabular}

Fuente: Consorcio Agua Azul (2011).

Tabla 4

Prueba de jarras con sulfato férrico

\begin{tabular}{|c|c|c|c|c|c|c|c|}
\hline & \multicolumn{2}{|c|}{ Mezcla rápida } & \multicolumn{4}{|c|}{ Floculación } & Sedimentación \\
\hline \multirow{3}{*}{$\begin{array}{c}\text { Jarras } \\
\mathbf{N}^{\circ}\end{array}$} & Tiempo (s) & 3 & $\begin{array}{l}\text { Tiempo } \\
\text { (minutos) }\end{array}$ & 6 & 6 & 6 & Tiempo (minutos) \\
\hline & $\begin{array}{l}\text { Velocidad } \\
\text { (RPM) }\end{array}$ & 300 & $\begin{array}{l}\text { Velocidad } \\
\text { (RPM) }\end{array}$ & 70 & 30 & 20 & 12 \\
\hline & Coag. (ml) & $\begin{array}{l}\text { Coag. } \\
\text { (ppm) }\end{array}$ & $\begin{array}{l}\text { Tiempo form. } \\
\text { floc (s) }\end{array}$ & \multicolumn{3}{|c|}{$\begin{array}{l}\text { Índice de Will- } \\
\text { comb }\end{array}$} & $\begin{array}{l}\text { Turbiedad resi- } \\
\text { dual (NTU) }\end{array}$ \\
\hline 1 & 0,5 & 10 & 225 & \multicolumn{3}{|c|}{6} & 2,54 \\
\hline 2 & 0,75 & 15 & 120 & \multicolumn{3}{|c|}{8} & 1,55 \\
\hline 3 & 1,00 & 20 & 80 & \multicolumn{3}{|c|}{8} & 2,00 \\
\hline 4 & 1,50 & 30 & 30 & \multicolumn{3}{|c|}{8} & 0,84 \\
\hline
\end{tabular}

Fuente: Consorcio Agua Azul (2011). 
En las tablas siguientes se observan las ventajas y desventajas que se presentan en el uso de ambos coagulantes.

Tabla 5

Sulfato de aluminio

\begin{tabular}{|c|c|}
\hline Ventajas & Desventajas \\
\hline $\begin{array}{l}\text { - Es el coagulante más usado, y domina el } \\
\text { mercado. } \\
\text { - Bajo costo. } \\
\text { - Manejo sencillo por parte del personal, } \\
\text { puesto que no requiere de cuidados espe- } \\
\text { ciales para su uso. } \\
\text { - No se modifica químicamente en el tiempo. }\end{array}$ & $\begin{array}{l}\text { - Si no se controla adecuadamente la } \\
\text { dosificación, la concentración de alumi- } \\
\text { nio residual puede exceder los límites } \\
\text { máximos permisibles establecidos para } \\
\text { la calidad del agua potable }(0,2 \mathrm{mg} / \mathrm{l}) \text {. } \\
\text { - Dependiendo de las características del } \\
\text { agua cruda, puede disminuir su eficien- } \\
\text { cia, por lo que requiere de un ayudante } \\
\text { de coagulación, lo que implica un mayor } \\
\text { costo. }\end{array}$ \\
\hline
\end{tabular}

Elaboración propia.

Tabla 6

Sulfato férrico

\begin{tabular}{ll}
\hline \multicolumn{1}{c}{ Ventajas } & \multicolumn{1}{c}{ Desventajas } \\
\hline - No produce aluminio residual. & - Su costo es más elevado en compa- \\
- En algunos casos, produce un floc más pe- & $\begin{array}{l}\text { ración con el Sulfato de aluminio. } \\
\text { sado y de mayor velocidad de asentamien- }\end{array}$ \\
to que el sulfato de aluminio. & Puede producir color en el agua. \\
- Puede trabajar con un rango de pH amplio. &
\end{tabular}

Elaboración propia.

\subsection{Sedimentación}

Es el proceso físico mediante el cual las partículas en suspensión presentes en el agua son removidas o separadas del fluido, debido al efecto de la gravedad. Dichas partículas deberán ser más densas que el agua, y el resultado que se obtenga será un fluido clarificado y una suspensión más concentrada. 
La remoción de partículas se puede conseguir dejando sedimentar el agua, filtrándola o ejecutando ambos procesos de manera consecutiva, por esta razón ambos procesos se consideran complementarios.

Entre los factores que influyen en la sedimentación podemos citar los siguientes:

- La calidad del agua (variación de concentración de materias en suspensión, temperatura del agua).

- Las condiciones hidráulicas.

- Procesos previos a la sedimentación.

Dependiendo del tipo de partícula que se remueva en cada unidad, los sedimentadores se clasifican en:

- Sedimentadores o decantadores estáticos.- En estas unidades se produce la sedimentación normalmente con caída libre. Se distinguen los siguientes tipos:

- Desarenadores: Tienen como objetivo eliminar la arena del agua cruda, evitando que estas partículas interfieran en la operación de las bombas y en los siguientes procesos.

- Unidades de flujo horizontal: Pueden ser sedimentadores de forma rectangular, circular o cuadrados. La remoción de lodos se puede hacer en forma continua o intermitente.

- Unidades de flujo vertical: Son unidades de forma cilíndrica.

- Unidades de flujo helicoidal: Se utilizan para tratar aguas con alto contenido de flóculos y que tengan alta velocidad de sedimentación.

- Decantadores dinámicos.- Requieren una alta concentración de partículas para incrementar las posibilidades de contacto en un manto de lodos, con una concentración de partículas de 10 a 20\% en volumen. Tenemos los siguientes tipos:

- Unidades de manto de lodos con suspensión hidráulica: La ventaja es que no tienen, generalmente, ninguna pieza removible dentro del tanque ni requieren energía eléctrica para funcionar; asimismo, es necesario evitar turbulencia en la entrada del agua, puesto que esto afectaría al manto de lodos.

- Unidades de manto de lodos con suspensión mecánica: Pueden ser de agitación, de separación y pulsante o de vacío. 
- Decantadores laminares.- Son aquellos cuya eficiencia decrece a medida que aumenta la carga superficial en las celdas, también depende de las características del agua tratada y del diseño del sedimentador.

- Decantadores laminares de flujo horizontal: Con láminas planas paralelas inclinadas (ángulo de $5^{\circ}$ ), para obtener la pendiente adecuada que favorezca el escurriendo de los flóculos.

- Decantadores laminares de flujo inclinado: Con módulos instalados con un ángulo de $60^{\circ}$. El sistema de módulos facilita la decantación de sólidos, por acortar el recorrido de deposición de las partículas sólidas e inducir a que el flujo del agua sea laminar.

Un ejemplo de este tipo de sedimentador se encuentra en la planta de tratamiento de agua del Consorcio Agua Azul S.A.; en el que durante el mes de marzo se han obtenido los siguientes datos que nos indican que las turbiedades a la salida de estos sedimentadores fluctúan entre 2 y 4 NTU, lo cual es adecuado para no colmatar los filtros y obtener turbiedades a la salida de estos menores a 1 NTU, cumpliendo de esta manera con los estándares de calidad para el agua potable.

Tabla 7

Turbiedades de las unidades de tratamiento

\begin{tabular}{ccc}
\hline $\begin{array}{c}\text { Turbiedad de agua cruda } \\
\text { en mezcla rápida (NTU) }\end{array}$ & $\begin{array}{c}\text { Turbiedad de agua } \\
\text { sedimentada (NTU) }\end{array}$ & $\begin{array}{c}\text { Turbiedad del agua } \\
\text { filtrada (NTU) }\end{array}$ \\
\hline 30 & 1,42 & 0,22 \\
53,2 & 3,21 & 0,29 \\
49,9 & 2,23 & 0,20 \\
39,3 & 1,31 & 0,14 \\
37,7 & 2,45 & 0,16 \\
28,2 & 3,00 & 0,25 \\
41,4 & 2,86 & 0,21 \\
47,6 & 2,72 & 0,19 \\
36,6 & 3,95 & 0,19 \\
68,4 & 3,34 & 0,19 \\
\hline
\end{tabular}

Fuente: Consorcio Agua Azul (2011).

La figura 3 muestra un sedimentador laminar que cuenta con dos secciones paralelas denominadas naves, las que están provistas de una 
fila de módulos formados por planchas onduladas de polipropileno e instaladas con un ángulo de $60^{\circ}$. El flujo de agua clarificada en cada nave es ascendente y es transportado por un sistema de tuberías de PVC hacia un canal central abierto que separa las naves. Cada módulo tiene en su parte inferior tolvas de recolección de lodos (figura 4).

Figura 3

Sedimentadores laminares

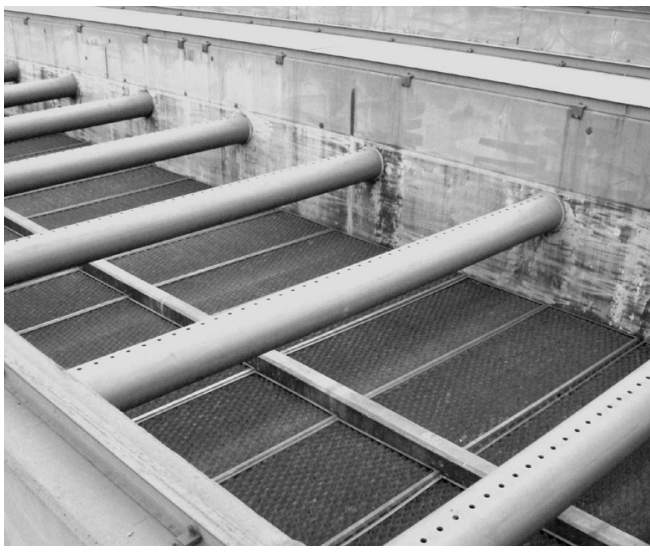

Fuente: Consorcio Agua Azul (2011).
Figura 4 Tolvas de recolección de lodos

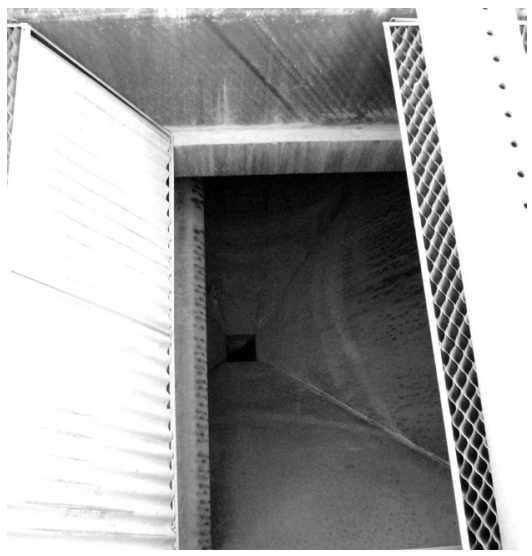

Fuente: Consorcio Agua Azul (2011).

\subsection{Filtración}

Es un proceso que consiste en la separación de partículas y pequeñas cantidades de microorganismos (bacterias, virus) a través de un medio poroso. Es la fase responsable de que se cumplan los estándares de calidad para el agua potable. Desde el punto bacteriológico, los filtros tienen una eficiencia de remoción superior a 99\%.

El tamaño de las partículas que quedan retenidas en mayor o menor proporción en los granos del lecho filtrante varía desde flóculos de $1 \mathrm{~mm}$ hasta coloides, bacterias y virus inferiores a $10^{-3} \mathrm{~mm}$. Cuando el floc tiene un volumen mayor que el de los poros del lecho filtrante quedará retenido por cernido en los intersticios del lecho; sin embargo, en el caso de las bacterias cuyo tamaño es mucho menor que el de los poros quedarán removidas por una serie de fenómenos.

En la filtración se producen las siguientes etapas complementarias: 
- Transporte de las partículas dentro de los poros.- Es un fenómeno físico e hidráulico, que está influenciado por parámetros que gobiernan la transferencia de masas. Los mecanismos que pueden realizar transporte son: cernido, sedimentación, intercepción, difusión, impacto inercial y acción hidrodinámica.

- Adherencia a los granos del medio.- Es un fenómeno de acción superficial, que está influenciado por parámetros físicos y químicos. Los mecanismos que pueden realizar adherencia son: fuerzas de Van der Waals, fuerzas electroquímicas y puente químico.

Las unidades de filtración se clasifican teniendo en cuenta los siguientes parámetros:

- Lecho filtrante.- Simple (arena o antracita) y lechos dobles o múltiples.

- Sentido del flujo.- Descendente, ascendente y ascendente-descendente.

- Forma de aplicar la carga de agua sobre el lecho.- A gravedad y a presión.

- Forma de control operacional.- Tasa constante y nivel variable, tasa constante y nivel constante y tasa declinante.

Los factores que influyen en la filtración son:

- Características de la suspensión: Tipo, tamaño, densidad, dureza o resistencia de las partículas suspendidas (flóculos), temperatura del agua por filtrar y concentración de partículas suspendidas en el afluente.

- Características del medio filtrante: Tipo, granulometría, peso específico del material filtrante y espesor de la capa filtrante.

- Características hidráulicas: Tasa de filtración, carga hidráulica disponible para la filtración, método de control de los filtros y calidad del efluente.

Durante la filtración, los granos del medio filtrante retienen las partículas hasta obstruir el paso del flujo, por lo que requieren ser lavados periódicamente. La turbiedad del agua filtrada no debe ser mayor de una NTU, con un color menor a 5 UCV.

La figura 5 representa un filtro de gravedad con lecho de arena, flujo descendente y tasa declinante. El lavado de este filtro de arena se efectúa deteniendo el ingreso de agua a este, simultáneamente se abre 
la compuerta de lavado de tal manera que al disminuir bruscamente el nivel de agua dentro del filtro, el agua filtrada contenida en los canales laterales invierte su patrón de flujo debido a que tienen un mayor nivel, realizándose así el retrolavado que agita el lecho de arena y elimina las partículas por medio del canal de lavado. Luego de terminado el retrolavado se cierra la compuerta de lavado y se abre la compuerta de ingreso para restablecer el proceso de filtrado.

Figura 5

Filtros de gravedad

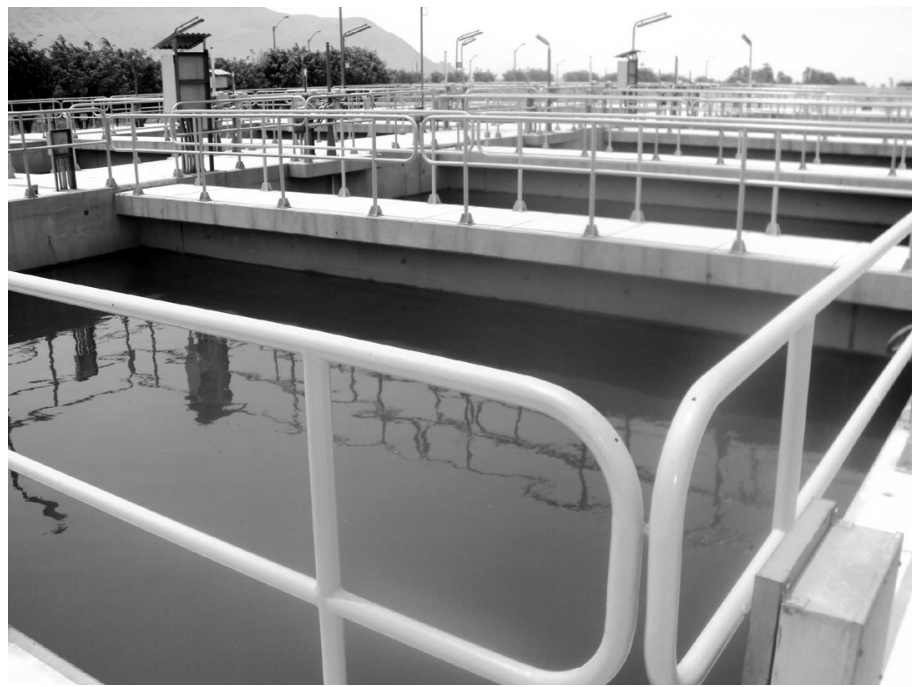

Fuente: Consorcio Agua Azul (2011).

\subsection{Desinfección}

Es el último proceso de tratamiento del agua, que consiste en la destrucción selectiva de los organismos potencialmente infecciosos. Lo que significa que no todos los organismos patógenos son eliminados en este proceso, por lo que requieren procesos previos como la coagulación, sedimentación y filtración para su eliminación.

Los factores que influyen en la desinfección son:

- Los microorganismos presentes y su comportamiento.

- La naturaleza y concentración del agente desinfectante.

- La temperatura del agua. 
- La naturaleza y calidad del agua.

- El pH del agua.

- El tiempo de contacto.

La efectividad de la desinfección se mide por el porcentaje de organismos muertos dentro de un tiempo, una temperatura y un $\mathrm{pH}$ prefijados. La resistencia de estos microorganismos varía, siendo las esporas bacterianas las más resistentes, le siguen en resistencia los quistes de protozoarios, virus entéricos y por último las bacterias vegetativas (coliformes).

La presencia de sólidos reduce la eficacia de la desinfección debido a que los organismos asociados a estos sólidos pueden estar protegidos de la acción del agente desinfectante físico o químico. Los agentes químicos más importantes son el cloro, el bromo, el yodo, el ozono, el permanganato de potasio, el agua oxigenada y los iones metálicos. Los agentes físicos más usados son los sistemas de coagulación-floculación, sedimentación, filtración, el calor, la luz y los rayos ultravioleta.

El cloro es el agente desinfectante más importante; puede utilizarse en forma de gas, de líquido o de sal (hipoclorito de sodio). Es de fácil aplicación, manejo sencillo y bajo costo. En dosis adecuadas no produce riesgos para el hombre ni para los animales. Su efecto residual protege al agua de contaminarse en las redes de distribución.

Es importante tomar precauciones en el uso del cloro, debido a la formación de trihalometanos, los cuales son considerados potencialmente peligrosos.

La Agencia para la Protección del Ambiente de Estados Unidos ha fijado un límite máximo permisible de $0,08 \mathrm{mg} / \mathrm{l}$ para los trihalometanos en el agua para consumo humano.

\section{PLANTAS DE TRATAMIENTO DE AGUA}

Es una instalación donde el agua cruda es sometida a diversos procesos con el objetivo de eliminar los microorganismos y los contaminantes físicos y químicos hasta los límites aceptables que estipulan las normas.

De acuerdo con el tipo de procesos que las forman, las plantas de tratamiento se clasifican en plantas de filtración rápida y plantas de filtración lenta. 
Según la tecnología usada se pueden clasificar en plantas convencionales antiguas, plantas convencionales de tecnología apropiada y plantas de tecnología importada o de patente.

Un ejemplo de una planta de tratamiento de filtración rápida es la planta de tratamiento de agua de Consorcio Agua Azul S. A., ubicada en el kilómetro 26,5 de la carretera a Canta, en el distrito de Carabayllo.

Dicho consorcio es la empresa concesionaria del proyecto Aprovechamiento Óptimo de las aguas Superficiales y Subterráneas del Río Chillón, que se dedica a la producción de agua potable para la empresa de Servicio de Agua Potable y Alcantarillado de Lima (Sedapal), y abastece a los distritos de Comas, Carabayllo, Puente Piedra, Santa Rosa, Ventanilla y Ancón.

Durante la época de avenida del río, que comprende los meses de diciembre hasta abril, se realiza la captación de aguas superficiales $\left(5 \mathrm{~m}^{3} / \mathrm{s}\right)$ para su tratamiento y posterior entrega y produce $2 \mathrm{~m}^{3} / \mathrm{s}$ de agua potable. En la época de estiaje, de mayo a noviembre, el abastecimiento proviene de las aguas subterráneas (28 pozos) y entrega $1 \mathrm{~m}^{3} / \mathrm{s}$ de agua potable.

Se requiere que la planta de tratamiento sea compacta, eficiente y de mínimos costos de operación. Se desarrollan los siguientes procesos:

- Coagulación: la inyección de coagulante se realiza en los seis canales Parshall que constituyen la unidad de mezcla rápida.

- Floculación: se realiza en seis canales de floculación con pantallas y flujo vertical.

- Sedimentación: cuenta con tres unidades de sedimentadores laminares de placas inclinadas.

- Filtración: se dispone de 16 filtros de gravedad y con lecho de arena.

- Desinfección: se realiza la precloración y poscloración del agua.

La diferencia de alturas de la planta de tratamiento hace que esta funcione por gravedad, aprovechando la energía potencial del agua y evitando la instalación de equipos electromecánicos, de uso común para la tecnología de potabilización. Comprende los siguientes procesos:

- La mezcla rápida del coagulante se hace aprovechando el resalto hidráulico en los canales Parshall, sin mezcladores de alta velocidad con accionamiento eléctrico. 
- La floculación se realiza de manera hidráulica en canales con adecuada gradiente de velocidad, sin agitadores lentos para floculación con accionamiento eléctrico.

- El retrolavado de los filtros de arena se hace manteniendo un tirante de agua filtrada en el canal aguas abajo de los mismos filtros, suficiente para la operación de lavado a una velocidad apropiada, sin bombas ni sopladores de aire con motores eléctricos de alta potencia.

Los únicos equipos eléctricos con funcionamiento continuo son las bombas para dosificación de productos químicos, en la precloración o desinfección final del efluente (poscloración) y para algunos servicios de la planta.

En la tabla 8 se describen los beneficios y costos de trabajar con el sistema de planta y de pozos.

Tabla 8

Beneficios y costos

\begin{tabular}{ll}
\hline \multicolumn{1}{c}{ Operación de planta } & \multicolumn{1}{c}{ Operación de pozos } \\
\hline - Produce $2 \mathrm{~m} / \mathrm{s}$ de agua potable. & - Producen en conjunto $1 \mathrm{~m} / \mathrm{s}$ de agua \\
- Consumo de productos químicos: & potable. \\
sulfato de aluminio y cloro en la pre- & - Consumo de productos químicos: solo \\
cloración y poscloración, además & cloro en la poscloración. Por ejemplo: \\
de otros. Por ejemplo: para el mes & en el mes de noviembre del $2010 \mathrm{se}$ \\
de abril del presente año se con- & consumieron en total $1.877 \mathrm{~kg}$. \\
sumieron $12.748 \mathrm{~kg}$ de cloro en la & - Consumo de energía eléctrica. En el \\
precloración y $5.888 \mathrm{~kg}$ de cloro en la & mes de noviembre del $2010 \mathrm{se}$ consu- \\
poscloración. & mieron $957.379 \mathrm{~kW} / \mathrm{h}$. \\
- Consumo de energía eléctrica. En el & \\
mes de marzo del presente año se & \\
consumieron $79.745 \mathrm{~kW} / \mathrm{h}$. &
\end{tabular}

Fuente: Consorcio Agua Azul (2011).

El problema que se observa en la época de pozos es que el nivel de estos va disminuyendo, lo que trae como consecuencia que la eficiencia de las bombas también disminuya.

Por otro lado, también se debe conocer la problemática que presenta el río Chillón. Este tiene su origen en las lagunas Chuchón y Chonta, a $4.850 \mathrm{msnm}$. Recorre una distancia de $126 \mathrm{~km}$, y tiene una pendiente 
promedio de 3,85\%. Constituye la segunda fuente de agua para Lima. En los meses de enero a abril de este año ha registrado un caudal que sobrepasa los $10 \mathrm{~m}^{3} / \mathrm{s}$, de los cuales $5 \mathrm{~m}^{3} / \mathrm{s}$ son aprovechados para producir agua potable; el caudal restante se pierde en el mar. La contaminación del río Chillón como consecuencia del crecimiento urbano, de las actividades clandestinas (chancherías), agrícolas, industriales, etcétera, ha ido en aumento y requiere la atención prioritaria por parte de la población y de las autoridades competentes.

\section{CONCLUSIONES}

- La aplicación de políticas de prevención en las fuentes de agua superficial evitarían los diferentes grados de contaminación de este recurso y por consiguiente los tratamientos costosos para hacerla potable.

- Un adecuado proceso de coagulación-floculación se verá reflejado en el proceso de sedimentación, debido a que los flóculos formados quedarán retenidos fácilmente en los sedimentadores, obteniéndose turbiedades bajas que ayudarán a incrementar la eficiencia de los filtros.

- Es importante una adecuada dosificación de cloro para evitar la formación de productos nocivos para la salud, como los trihalometanos.

- Se debe considerar el posible tratamiento de las aguas residuales generadas para devolverlas en las mismas condiciones en que fueron captadas, cumpliendo de esta manera con los límites de vertido establecidos por el organismo competente.

- El agua es un recurso limitado, por lo tanto es necesario tomar medidas que garanticen un manejo racional de este por parte de la población.

\section{BIBLIOGRAFÍA}

Arboleda, Jorge (2000). Teoría y práctica de la purificación del agua. Tomos 1 y 2. Bogotá: McGraw-Hill.

CEPIS, OPS /OMS (2004/2006). Tratamiento de agua para consumo humano. Manual I: Teoría. Tomos I y II. Lima. 
Consorcio Agua Azul S.A. (2011). Aprovechamiento óptimo de las aguas superficiales y subterráneas del Río Chillón. Lima. <http://www. caa.com.pe/> [Consulta: 25 de abril del 2011.]

Fundación Universitaria Iberoamericana (Funiber). Programa Máster en Gestión Integrada (2011). Medio ambiente, calidad y prevención. Tomo I. Barcelona.

Rosasco, Otto (2006). "Abastecimiento, Contaminación y Problemática del Agua en el Perú". Simposio. Anales 2006. Lima. <http://www. acadnacmedicina.org.pe/publicaciones/Anales_2006/absatecimiento_contaminacion_rosasco.pdf $>$. [Consulta: 14 de abril del 2011.]

Sunass (2000). Parámetros de calidad y límites máximos permisibles. Lima. <http://www.sunass.gob.pe/doc/normas\%20legales/legisla\%20web(cambio)/normas/calidad\%20de\%20agua/Oficio\%20 677.pdf>. [Consulta: 4 de abril del 2011.] 